\title{
Sodium bicarbonate intake improves high-intensity intermittent exercise performance in trained young men
}

\author{
Peter Krustrup ${ }^{1,2}$, Georgios Ermidis ${ }^{3}$ and Magni Mohr ${ }^{4,5^{*}}$
}

\begin{abstract}
Background: Sodium bicarbonate intake has been shown to improve exercise tolerance, but the effects on high-intensity intermittent exercise are less clear. Thus, the aim of the present study was to determine the effect of sodium bicarbonate intake on Yo-Yo intermittent recovery test level 2 performance in trained young men.

Method: Thirteen men aged $23 \pm 1$ year (height: $180 \pm 2 \mathrm{~cm}$, weight: $78 \pm 3 \mathrm{~kg} ; \mathrm{VO}_{2} \max : 61.3 \pm 3.3 \mathrm{mlO} \cdot \mathrm{kg}^{-1} \cdot \mathrm{min}^{-1}$; means \pm SEM) performed the Yo-Yo intermittent recovery test level 2 (Yo-Yo IR2) on two separate occasions in randomized order with (SBC) and without (CON) prior intake of sodium bicarbonate $\left(0.4 \mathrm{~g} \cdot \mathrm{kg}^{-1}\right.$ body weight). Heart rate and rating of perceived exertion (RPE) were measured during the test and venous blood samples were taken frequently.

Results: Yo-YO IR2 performance was $14 \%$ higher $(P=0.04)$ in SBC than in CON (735 \pm 61 vs $646 \pm 46 \mathrm{~m}$, respectively). Blood $\mathrm{pH}$ and bicarbonate were similar between trials at baseline, but higher $(\mathrm{P}=0.003)$ immediately prior to the Yo-YO IR2 test in SBC than in CON (7.44 \pm 0.01 vs $7.32 \pm 0.01$ and $33.7 \pm 3.2 \mathrm{vs} 27.3 \pm\left. 0.6 \mathrm{mmol} \cdot\right|^{-1}$, respectively). Blood lactate was $0.9 \pm 0.1$ and $0.8 \pm 0.1 \mathrm{mmol} \cdot \mathrm{I}^{-1}$ at baseline and increased to $11.3 \pm 1.4$ and $9.4 \pm 0.8 \mathrm{mmol} \cdot \mathrm{I}^{-1}$ at exhaustion in SBC and $C O N$, respectively, being higher $(P=0.03)$ in SBC. Additionally, peak blood lactate was higher $(P=0.02)$ in SBC than in CON (11.7 $\left.\pm 1.2 \mathrm{vs} 10.2 \pm 0.7 \mathrm{mmol} \cdot \mathrm{I}^{-1}\right)$. Blood glucose, plasma $\mathrm{K}^{+}$and $\mathrm{Na}^{+}$were not different between trials. Peak heart rate reached at exhaustion was $197 \pm 3$ and $195 \pm 3 \mathrm{bpm}$ in SBC and CON, respectively, with no difference between conditions. RPE was $7 \%$ lower $(P=0.003)$ in SBC than in CON after $440 \mathrm{~m}$, but similar at exhaustion $(19.3 \pm 0.2$ and $19.5 \pm 0.2)$.

Conclusion: In conclusion, high-intensity intermittent exercise performance is improved by prior intake of sodium bicarbonate in trained young men, with concomitant elevations in blood alkalosis and peak blood lactate levels, as well as lowered rating of perceived exertion.
\end{abstract}

Keywords: Fatigue, Yo-Yo IR2 performance, Blood pH and lactate, Plasma potassium, Buffer capacity

\section{Background}

For decades, it has been proposed that muscle acidosis is associated with muscle fatigue during intense exercise [1]. Acidification has been suggested to negatively affect a myriad of steps in the excitation-contraction coupling in the muscle cell, such as activity in the myosin ATPase, $\mathrm{Ca}^{2+}$ ATPase and $\mathrm{Na}^{+}-\mathrm{K}^{+}$ATPase [2], to

\footnotetext{
* Correspondence: magnim@setur.fo

${ }^{4}$ Faculty of Natural and Health Sciences, University of the Faroe Islands, Jónas Broncks gøta 25. 3rd floor, Tórshavn, Faroe Islands

${ }^{5}$ Department of Food and Nutrition, and Sport Science, Center of Health and Human Performance, University of Gothenburg, Gothenburg, Sweden Full list of author information is available at the end of the article
}

attenuate the $\mathrm{K}^{+}$efflux through $\mathrm{pH}$-sensitive potassium channels $[3,4]$ and to impair the activity of metabolic enzymes [1]. During high-intensity intermittent exercise performed in team sports, the high number of intense actions challenges the acid-base homeostasis in the muscle $[5,6]$ and may, consequently, impair exercise tolerance. Interventions that promote the buffer capacity in the blood and/or muscles may therefore be beneficial in intense intermittent sports.

The Yo-Yo intermittent recovery test level 2 (Yo-Yo IR2) has been demonstrated to have a marked anaerobic component [7]. For example, muscle $\mathrm{pH}$ levels below 6.8

\section{() Biomed Central}


have been measured at exhaustion, indicating a high taxation of the acid-base balance in the muscle cell. In addition, Yo-Yo IR2 performance has been shown to correlate to the amount of intense running during the most intense periods in team sport games [8], making the test suitable for studying team-sport-specific exercise with a high anaerobic energy contribution.

Several interventions have been carried out to manipulate the acid-base environment prior to intense exercise, such as drug manipulations $[9,10]$ and prior arm exercise [11], demonstrating a significant effect on exercise tolerance. For example, $\beta$-alanine supplementation has been shown to be beneficial during high-intensity intermittent exercise by increasing the muscle carnosine buffer system $[10,12]$. The use of sodium bicarbonate supplementation in order to study fatigue resistance during intense exercise protocols has been widely applied and used by athletes for the last 80 years [13], and a moderate effect size on the influence of the drug on exercise performance has been demonstrated [14]. Bicarbonate doses of $0.3-0.5 \mathrm{~g} \cdot \mathrm{kg}^{-1}$ body weight have been proposed for inducing consistent performance enhancements in a trained athlete population (for review, see [15]). Some of these studies have also applied teamsports-specific testing protocols $[16,17]$. However, to the best of our knowledge no studies have investigated the consequence of sodium bicarbonate supplementation on team-sport-specific exercise that correlates with performance during the most intense periods in competitive match-play and where muscle acidosis has been demonstrated to by high [8].

Thus, the aim of the present study was to examine the effect of oral sodium bicarbonate $\left(0.4 \mathrm{~g} \cdot \mathrm{kg}^{-1}\right.$ body weight) ingestion on Yo-Yo IR2 performance and physiological response in trained athletes familiar with high-intensity intermittent exercise in training and competition. We hypothesized that sodium bicarbonate intake would result in a more alkaline physiological environment and improve high-intensity intermittent exercise tolerance.

\section{Methods}

\section{Participants}

Thirteen trained male athletes (age: $23 \pm 1$ year, height: $180 \pm 2 \mathrm{~cm}$, weight: $78 \pm 3 \mathrm{~kg}$ ). The athletes had a $\mathrm{VO}_{2} \max$ of $61.3 \pm 3.3 \mathrm{mlO} \cdot \mathrm{kg}^{-1} \cdot \mathrm{min}^{-1}$ determined by a bicycle ramp-test and were competing in intense sports (middle-distance running, team sports and triathlon) training 5-7 times per week and with a consistent training history of $>4$ years were recruited to the study. The participants were fully informed of the risks and discomforts associated with the experimental procedures and all provided written consent. The study was approved by the Institutional Research
Ethics Committee and conformed to the code of ethics of the Declaration of Helsinki.

\section{Design}

The athletes reported to the laboratory on three separate occasions over a 12-day period. On visit 1 , they were familiarized with the Yo-Yo intermittent recovery test level 2 (Yo-Yo IR2; see [7]). The subjects were then assigned in a randomised, crossover design to perform the Yo-Yo IR2 test with (SBC) and without $(\mathrm{CON})$ prior intake of sodium bicarbonate. The test leader was blinded, but no placebo was used in the control trials due to the stomach effects of bicarbonate intake (see [15]). On each experimental visit (2 and 3), the first 2 min of the Yo-Yo IR1 test were completed as a warm-up before the experimental procedures [7]. Venous blood samples were obtained before, during and after the tests as previously described [18], and heart rate (HR) was recorded continuously throughout the experiment (Polar RS400, Polar Electro Oy, Kempele, Finland). Rating of perceived exertion was assessed during the test as described by Borg [19]. The experimental trials were carried out at the same time of day $( \pm 1$ h). Participants were asked to record their food intake in the $24 \mathrm{~h}$ preceding the first experimental trial and to replicate the same diet in the $24 \mathrm{~h}$ preceding the subsequent trial. Subjects were instructed to arrive at the laboratory in a rested and fully hydrated state $\geq 3 \mathrm{~h}$ post-prandially and to avoid strenuous exercise in the $24 \mathrm{~h}$ preceding each experimental trial. Subjects were also asked to refrain from caffeine and alcohol in the preceding $24 \mathrm{~h}$.

\section{Experimental procedure}

Upon arrival at the laboratory, a cannula (Insyte- $\mathrm{W}^{\mathrm{TM}}$, Becton Dickinson, Madrid, Spain) was inserted into an antecubital vein to enable frequent blood sampling before, during and after the test. The Yo-Yo IR2 test was performed indoors on a wooden surface on running lanes with a width of $2 \mathrm{~m}$ and a length of $20 \mathrm{~m}$. The Yo-Yo IR2 test has been described and evaluated in detail previously $[7,8]$ and used as an experimental model in other intervention studies on fatigue during high-intensity intermittent exercise $[18,20]$. Briefly, it consists of repeated 20-m runs at progressively increased speeds controlled by audio beeps from a CD player. Each running bout is followed by a 10-s active recovery period in which the subject jogs around a marker placed $5 \mathrm{~m}$ behind the starting line (for details, see [21]). When a subject twice fails to reach the finishing line in time, the distance covered is recorded and this represents the test result. Blood was sampled at rest (baseline) prior to the Yo-Yo IR2 test, as well as after 160, 280, 440 and $600 \mathrm{~m}$, and at exhaustion in the Yo-Yo IR2 test. In addition, 
blood was collected at 1, 3 and 5 min of recovery after the test. Blood lactate and glucose, as well as plasma potassium and sodium concentrations, were analyzed in all samples. Blood $\mathrm{pH}$ and bicarbonate was analyzed at baseline, immediately before the Yo-Yo IR2 test and at exhaustion.

\section{Supplementation}

After completing the familiarization test, the subjects were assigned in a single-blind, randomized, crossover design to consume sodium bicarbonate $\left(0.4 \mathrm{~g} \cdot \mathrm{kg}^{-1}\right.$ body weight, $\mathrm{SBC}$ ) or no supplement $(\mathrm{CON})$. The sodium bicarbonate protocol used in the present study causes a slight stomach discomfort. Therefore the intake was not blinded for the subjects, as also described by others [15]. The sodium bicarbonate was evenly distributed in $\sim 25$ gelatin capsules, with one fifth taken at 90, 80, 70, 60 and $50 \mathrm{~min}$ prior to exercise, which has been shown to raise blood $\mathrm{pH}$ and bicarbonate concentration in pilot experiments.

\section{Blood and plasma analyses}

Blood samples were drawn into 5-mL heparin syringes (Terumo Corporation, Leuven, Belgium). $200 \mu \mathrm{L}$ of blood was immediately haemolysed in $200 \mu \mathrm{L}$ of ice-cold Triton X-100 buffer solution (Triton X-100, Amresco, Salon, $\mathrm{OH}$ ) and analysed to determine blood [lactate] and [glucose] within $\sim 5 \mathrm{~min}$ of collection (YSI 2300, Yellow Springs Instruments, Yellow Springs, OH). The remaining whole blood was then centrifuged at 4000 rpm for 3 min (Hetting EBA 20, Tuttlingen, Germany) before plasma was extracted and stored on ice for $\sim 30 \mathrm{~min}$ prior to being frozen at $-80^{\circ} \mathrm{C}$ for subsequent analysis of plasma $\left[\mathrm{K}^{+}\right]$and $\left[\mathrm{Na}^{+}\right]$(9180 Electrolyte Analyzer, F. Hoffmann-La Roche, Basel, Switzerland). Blood samples for $\mathrm{pH}$ and bicarbonate analyses were drawn in $2.5-\mathrm{mL}$ syringes and analysed instantly by an ABL acid-base analyser (Radiometer, Brønshøj, Denmark) [22].

\section{Rating of perceived exertion (RPE)}

RPE was assessed at 160, 280, $440 \mathrm{~m}$ and exhaustion according to the 20-stage Borg scale [19].

\section{Statistical analyses}

Differences between SBC and CON in Yo-Yo IR2 performance were analyzed using a paired-samples t-test. Differences between SBC and CON in blood and plasma variables were analyzed using a two-way ANOVA with repeated measures (supplement $\mathrm{x}$ time). If a significant F-value was observed, a Tukey post-hoc test was used to identify the points of difference. Statistical significance was accepted at $P<0.05$. Results are presented as mean \pm SEM unless stated otherwise.

\section{Results}

\section{Performance}

Yo-Yo IR2 performance was $735 \pm 61 \mathrm{~m}$ in SBC, which was $14 \%$ higher $(\mathrm{P}=0.04)$ than in $\mathrm{CON}(646 \pm 46 \mathrm{~m}$; Fig. 1). Nine of the thirteen subjects had a better Yo-Yo IR2 performance in the SBC trial, three had the same performance level, and one performed better in the CON trial (Fig. 1).

\section{Blood and plasma metabolites}

Blood $\mathrm{pH}$ was $7.37 \pm 0.01$ at baseline in SBC and CON, but increased $(\mathrm{P}=0.002)$ to $7.44 \pm 0.01$ in $\mathrm{SBC}$ before the Yo-Yo IR2 test and decreased $(\mathrm{P}=0.005)$ in $\mathrm{CON}$ (7.32 \pm 0.01 ; Fig. 2a). At exhaustion, blood $\mathrm{pH}$ decreased $(\mathrm{P}<0.001)$ to $7.19 \pm 0.04$ and $7.04 \pm 0.03$ in $\mathrm{SBC}$ and $\mathrm{CON}$, respectively, being higher $(\mathrm{P}<0.04)$ in $\mathrm{SBC}$ (Fig. 2a).

Blood [bicarbonate] was $28.3 \pm 0.5$ and $28.0 \pm 0.4$ $\mathrm{mmol} \cdot \mathrm{l}^{-1}$ at baseline, but rose $(\mathrm{P}<0.003)$ in SBC before the Yo-Yo IR2 test $\left(33.7 \pm 3.2 \mathrm{mmol} \cdot \mathrm{l}^{-1}\right)$ and was unchanged in $\mathrm{CON}\left(27.3 \pm 0.6 \mathrm{mmol} \cdot \mathrm{l}^{-1}\right)$ compared to baseline. At exhaustion, blood [bicarbonate] declined $(\mathrm{P}<0.001)$ in SBC and CON $(25.2 \pm 2.6$ and $20.2 \pm 0.8$ $\left.\mathrm{mmol} \cdot \mathrm{l}^{-1}\right)$. Pre-exercise and exhaustive blood [bicarbonate] was higher $(\mathrm{P}=0.01$ and 0.03$)$ in $\mathrm{SBC}$ than in CON (Fig. 2b).

Blood lactate was $0.9 \pm 0.1$ and $0.8 \pm 0.1 \mathrm{mmol} \cdot \mathrm{l}^{-1}$ at baseline and increased $(\mathrm{P}<0.001) 11.3 \pm 1.4$ and $9.4 \pm 0.8$ $\mathrm{mmol} \cdot \mathrm{l}^{-1}$ at exhaustion in SBC and CON, respectively, being higher $(\mathrm{P}=0.03)$ in SBC (Table 1). Additionally, peak blood lactate was higher $(\mathrm{P}=0.02)$ in $\mathrm{SBC}$ than in CON $\left(11.7 \pm 1.2\right.$ vs $\left.10.2 \pm 0.7 \mathrm{mmol} \cdot \mathrm{l}^{-1}\right)$.

Blood glucose rose $(\mathrm{P}<0.05)$ from $4.2 \pm 0.4$ and $4.1 \pm 0.2 \mathrm{mmol} \cdot \mathrm{l}^{-1}$ at baseline to $5.1 \pm 0.5$ and $5.2 \pm$ $0.6 \mathrm{mmol} \cdot \mathrm{l}^{-1}$ at exhaustion, with no difference between trials (Table 1 ).

Plasma $\left[\mathrm{K}^{+}\right]$rose $(\mathrm{P}<0.05)$ from $4.3 \pm 0.4$ and $4.2 \pm 0.4$ $\mathrm{mmol} \cdot \mathrm{l}^{-1}$ at baseline to $5.7 \pm 0.5$ and $5.8 \pm 0.6 \mathrm{mmol} \cdot \mathrm{l}^{-1}$ at exhaustion in $\mathrm{SBC}$ and $\mathrm{CON}$, respectively, with no differences between trials (Table 1). Plasma $\left[\mathrm{Na}^{+}\right]$was unchanged during the test and not different between conditions (Table 1).

\section{Heart rate and rating of perceived exertion}

Heart rate was $78 \pm 2$ and $79 \pm 2 \mathrm{bpm}$ at baseline and $91 \pm 3 \mathrm{bpm}$ pre exercise in $\mathrm{SBC}$ and $\mathrm{CON}$, respectively. Heart rate increased $(\mathrm{P}<0.05)$ during the test, reaching $197 \pm 3$ and $195 \pm 3 \mathrm{bpm}$ at exhaustion in $\mathrm{SBC}$ and $\mathrm{CON}$, respectively. No difference in heart rate response between conditions was determined during or after the test.

RPE was not different between trials after 160 and $280 \mathrm{~m}$ (SBC: $13.0 \pm 0.7$ and 14.8 \pm 0.7 ; CON: $13.1 \pm 0.7$ and $15.0 \pm 0.6$, respectively), but was $7 \%$ lower $(\mathrm{P}=0.003)$ after 


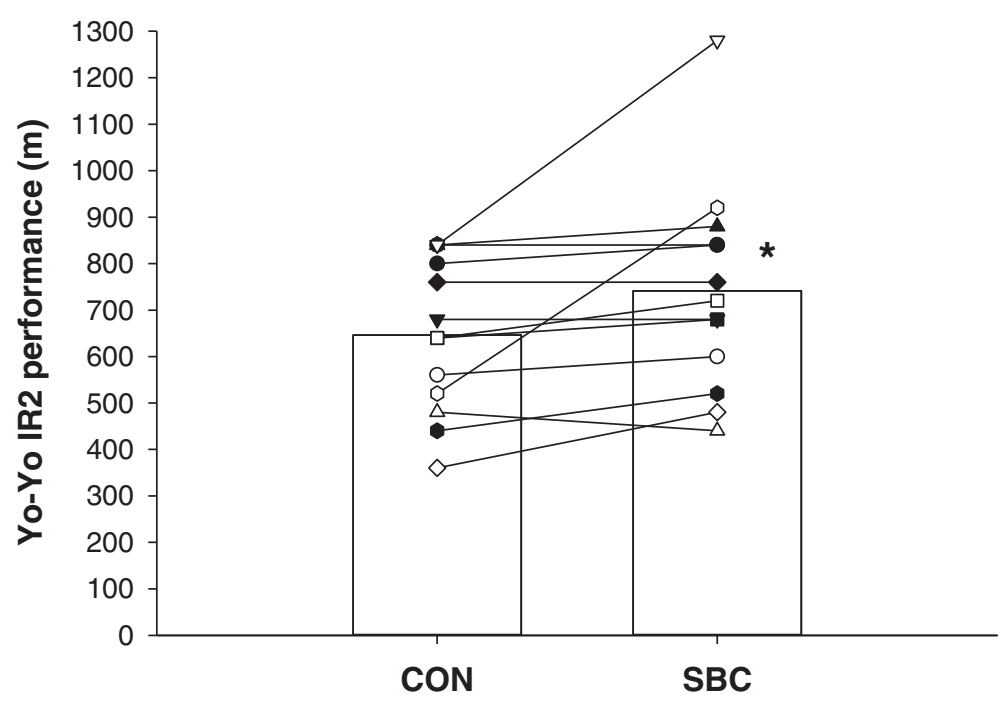

Fig. 1 Yo-Yo intermittent recovery test level 2 (Yo-Yo IR2) performance of trained young men $(n=13)$ on two separate occasions in randomized order with (SBC) and without (CON) prior intake of $0.4 \mathrm{~g} \cdot \mathrm{kg}^{-1}$ body weight sodium bicarbonate. Individual data and mean data are presented. *: Denotes significant difference between SBC and CON

$440 \mathrm{~m}$ in $\mathrm{SBC}$ than in $\mathrm{CON}(16.8 \pm 0.4$ vs $17.9 \pm 0.3)$. At exhaustion, RPE was similar in SBC and CON (19.3 \pm 0.2 and $19.5 \pm 0.2)$.

\section{Discussion}

In the present study, we observed that prior intake of sodium bicarbonate in capsular form using a protocol with gradual intake enhanced high-intensity intermittent exercise performance in young trained males. The performance improvement after sodium bicarbonate ingestion was accompanied by an elevated blood alkalosis and concentration of bicarbonate. In addition, blood lactate concentrations at exhaustion and peak values reached during the experimental protocol were higher, while the rating of perceived exertion was lower during intense exercise after sodium bicarbonate supplementation. In contrast, blood glucose, plasma $\mathrm{K}^{+}$and $\mathrm{Na}^{+}$as well as cardiovascular loading during high-intensity intermittent exercise were unaffected by sodium bicarbonate intake.

Performance in the Yo-Yo IR2 test increased by $14 \%$ after sodium bicarbonate intake, which is comparable to a $16 \%$ increase after caffeine intake in a comparable athlete population [18], but lower than a $34 \%$ improvement after $\beta$-alanine supplementation in football players [23]. In comparison, training studies report a 19-29 \% improvement in Yo-Yo IR2 performance observed after short-term periods (4-8 weeks) with speed endurance training in moderately trained [20] and well trained males [24]. Support for the performance improvement in the present study for the sodium bicarbonate intervention is provided, for example, by enhanced performance in the final sprints of a repeated sprint test $[16,25]$ and simulated boxing performance [17] after sodium bicarbonate intake, indicating an ergogenic effect during high-intensity exercise conditions performed under metabolic stress comparable to the short, intermittent and anaerobic Yo-Yo IR2 exercise protocol [7, 8, 21]. However, some studies applying intense exercise regimes such as Wingate testing report no beneficial effect of sodium bicarbonate supplementation (for review, see [14, 15]), indicating a predominant effect of sodium bicarbonate on highintensity intermittent exercise. According to a review by Carr et al. [15], sodium bicarbonate has a greater effect on trained individuals, so differences in training status may also partly explain the discrepancy between findings in different studies. In the present study, the subjects were well trained, having a maximal oxygen uptake comparable to top-class teamsport athletes and a Yo-Yo IR2 performance slightly below top-class central defenders in football [21]. Moreover, they were all involved in high-intensity sport, and the results indicate that this athlete population may benefit from sodium bicarbonate intake.

In the present study, we did not apply a placebo, since the gastrointestinal effects of high doses of bicarbonate are usually easy to trace [15]. A potential placebo effect may therefore have had an impact on the results, which is a limitation of the study design. However, in the present study a $14 \%$ improvement was seen in the sodium bicarbonate trial, with nine of the participants displaying an improvement and only one having a decline in performance. In comparison, the placebo effect on 
A)

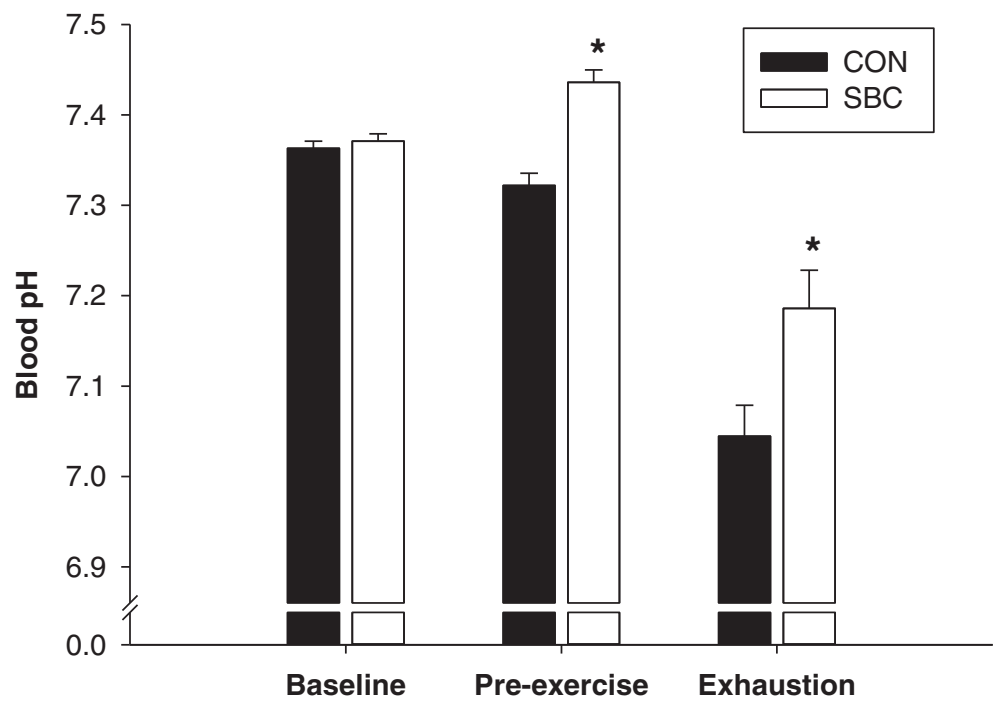

B)

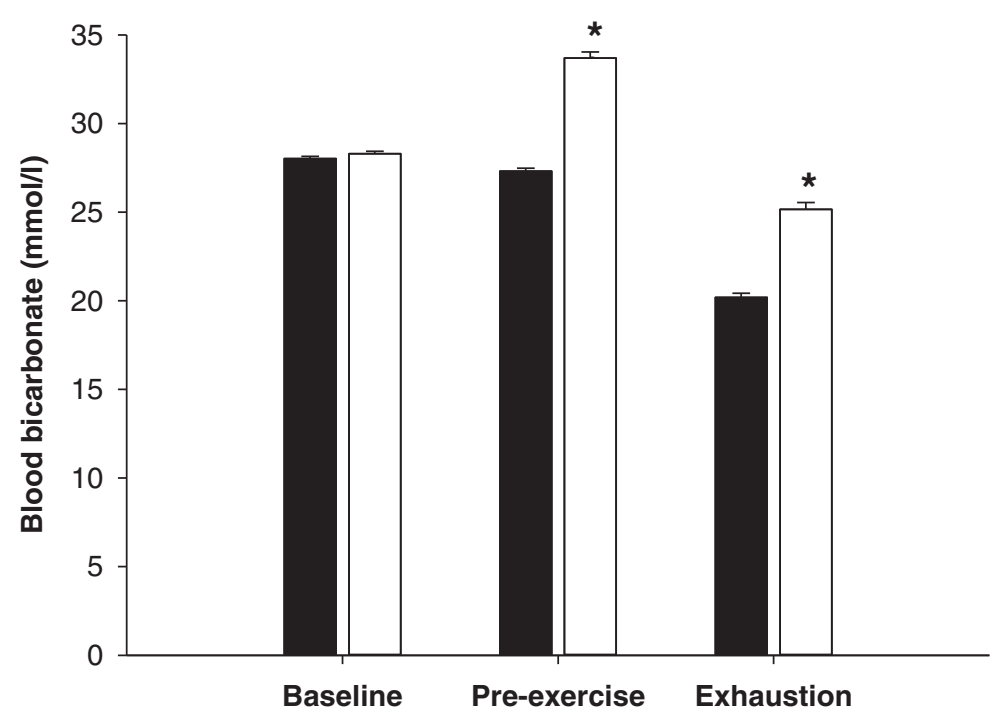

Fig. 2 Blood $\mathrm{pH}(\mathbf{a})$ and blood bicarbonate $(\mathbf{b})$ at baseline and immediately before and after the Yo-Yo IR2 test for trained young men ( $\mathrm{n}=13$ ) on two separate occasions in randomized order with (SBC) and without (CON) prior intake of $0.4 \mathrm{~g} \cdot \mathrm{kg}^{-1} \mathrm{body} \mathrm{weight} \mathrm{sodium} \mathrm{bicarbonate.} \mathrm{Data}$ are presented as means \pm SEM. *: Denotes significant difference between SBC and CON

high-intensity exercise performance reported in the literature is $1-3 \%$ [26]. There are two subjects that display a very large improvement in performance ( $\sim 50$ and $\sim 75 \%$; Fig. 1) and are likely to be highresponders to the sodium bicarbonate, which may have affected the results. However, even when these two outliers are omitted from the statistical analysis, there is still a significant $6 \%$ increase in Yo-Yo IR2 performance after sodium bicarbonate intake.

Part of the improvement in intermittent exercise performance may be explained by an elevated bicarbonateinduced buffer capacity in the blood, which will increase the muscle-to-blood $\mathrm{H}^{+}$gradient [27]. Before the start of the Yo-Yo IR2 test, blood bicarbonate was elevated by $23 \%$ in the sodium bicarbonate trial compared to control, with a significantly increased blood $\mathrm{pH}$ value. Thus, the blood buffer capacity was increased, which also resulted in higher blood $\mathrm{pH}$ and bicarbonate concentrations at exhaustions, despite a markedly longer exercise time in the intervention trial. The anaerobic contribution to the energy yield also appeared to be higher after the treatment with sodium bicarbonate, as reflected by the 15 and $20 \%$ higher peak blood lactate and exhaustion levels, which may also be associated with longer exercise time. 
Table 1 Blood and plasma metabolites during the Yo-Yo IR2 test

\begin{tabular}{|c|c|c|c|c|c|c|c|c|}
\hline & \multicolumn{2}{|c|}{ Blood lactate $\left(\mathrm{mmol} \cdot{ }^{\mathrm{I}-1}\right)$} & \multicolumn{2}{|c|}{ Blood glucose $\left(\mathrm{mmol} \cdot{ }^{\mid-1}\right)$} & \multicolumn{2}{|c|}{ Plasma K+ (mmol. $\left.{ }^{1-1}\right)$} & \multicolumn{2}{|c|}{ Plasma $\mathrm{Na}+\left(\mathrm{mmol} \cdot{ }^{\mid-1}\right)$} \\
\hline & SBC & CON & SBC & $\mathrm{CON}$ & SBC & $\mathrm{CON}$ & SBC & $\mathrm{CON}$ \\
\hline Baseline & $0.9 \pm 0.1$ & $0.8 \pm 0.1$ & $4.2 \pm 0.2$ & $4.1 \pm 0.2$ & $4.3 \pm 0.4$ & $4.2 \pm 0.4$ & $138 \pm 3$ & $138 \pm 4$ \\
\hline Pre-exercise: & $2.0 \pm 0.3$ & $1.7 \pm 0.2$ & $4.2 \pm 0.1$ & $4.3 \pm 0.1$ & $4.1 \pm 0.4$ & $4.2 \pm 0.4$ & $141 \pm 4$ & $139 \pm 4$ \\
\hline Level 17.2: & $2.8 \pm 0.5$ & $3.0 \pm 0.7$ & $4.3 \pm 0.1$ & $4.6 \pm 0.1$ & $4.8 \pm 0.5$ & $4.9 \pm 0.5$ & $144 \pm 4$ & $140 \pm 4$ \\
\hline Level 18.3: & $4.2 \pm 0.8$ & $4.1 \pm 0.7$ & $4.5 \pm 0.2$ & $4.5 \pm 0.2$ & $5.1 \pm 0.5$ & $5.2 \pm 0,5$ & $143 \pm 4$ & $143 \pm 4$ \\
\hline Level 19.4: & $6.3 \pm 1.1$ & $6.8 \pm 0.9$ & $4.5 \pm 0.3$ & $4.8 \pm 0.3$ & $5.6 \pm 0.6$ & $5.9 \pm 0.6$ & $145 \pm 4$ & $145 \pm 4$ \\
\hline Level 20.4: & $6.8 \pm 1.5$ & $6.2 \pm 0.5$ & $4.5 \pm 0.2$ & $4.9 \pm 0.2$ & $5.1 \pm 0.1$ & $5.5 \pm 0.2$ & $147 \pm 2$ & $144 \pm 2$ \\
\hline Exhaustion: & $11.3 \pm 1.4^{*}$ & $9.4 \pm 0.8$ & $5.1 \pm 0.5$ & $5.2 \pm 0.5$ & $5.7 \pm 0.5$ & $5.8 \pm 0.6$ & $150 \pm 4$ & $145 \pm 4$ \\
\hline 1 min recovery: & $9.9 \pm 1.1$ & $9.0 \pm 0.6$ & $5.0 \pm 0.5$ & $5.4 \pm 0.5$ & $4.4 \pm 0.4$ & $4.5 \pm 0.4$ & $148 \pm 4$ & $145 \pm 4$ \\
\hline 3 min recovery: & $10.4 \pm 1.1^{*}$ & $9.2 \pm 0.6$ & $5.9 \pm 0.6$ & $6.0 \pm 0.6$ & $3.8 \pm 0.4$ & $3.8 \pm 0.3$ & $146 \pm 4$ & $143 \pm 4$ \\
\hline 5 min recovery: & $10.3 \pm 1.2^{*}$ & $8.9 \pm 0.6$ & $5.8 \pm 0.6$ & $5.9 \pm 0.6$ & $3.4 \pm 0.3$ & $3.7 \pm 0.3$ & $145 \pm 4$ & $143 \pm 3$ \\
\hline
\end{tabular}

Blood lactate and glucose as well as plasma $\mathrm{K}+$ and $\mathrm{Na}+$ before, during and after a Yo-Yo IR2 performed in randomized order with (SBC) and without (CON) prior intake of sodium bicarbonate. Data are means \pm SEM

*Denotes a significant difference from CON. $\mathrm{P}<0.05$

Fatigue development during high-intensity intermittent exercise may be caused by a complex interplay between intra- and extracellular concentrations and gradients of ions such as $\mathrm{K}^{+}, \mathrm{Na}^{+}, \mathrm{Cl}^{-}$and $\mathrm{H}^{+}[28,29]$. In the present study, no differences were detected in plasma $\left[\mathrm{K}^{+}\right]$and $\left[\mathrm{Na}^{+}\right]$between the sodium bicarbonate and control trials. However, since the potential fatiguing effect of a homeostatic imbalance in these ions is exerted in the muscle interstitial compared to intracellular environment [28-32], a sodium bicarbonate induced effect on the kinetics of these ions during exercise cannot be ruled out. This is especially relevant to consider when the venous ion concentrations do not seem to reflect the interstitial values during intense exercise [30]. In support of a link between alkalosis and improved muscle $\mathrm{K}^{+}$ regulation, Street et al. [27] found, using the microdialysis technique in human skeletal muscle, that the interstitial $\mathrm{K}^{+}$accumulation rate during intense exercise was attenuated after drug-induced alkalosis.

In the present study, RPE was lowered after $440 \mathrm{~m}$ of running in the Yo-Yo IR2 test in the sodium bicarbonate trial compared to the control, despite the fact that the heart rate and blood lactate concentration at this timepoint were similar between trials. This may suggest that centrally mediated mechanisms were affected. The participants experienced less exertion late in the Yo-Yo IR2 test in the SBC trial when the heart rate was $>95 \%$ of $\mathrm{HR}_{\max }$ and blood lactate and plasma $\mathrm{K}^{+}$were markedly elevated. Moreover, although further distance was covered before exhaustion, the RPE scores remained the same as in the control trial at the point of fatigue. Thus, a higher performance level was achieved while reporting an equal level of perceived fatigue at exhaustion. Peripheral alterations are likely to lead to modulation of neural strategies, for example via group III and IV muscle afferents, widely distributed through muscle and responsive to a variety of chemical stimuli, including altered $\mathrm{H}^{+}$ $[33,34]$, which was lower in the present study after sodium bicarbonate intake. Thus, part of the improved performance after sodium bicarbonate treatment may relate to less negative feedback from the muscle and, thereby, less effect on the descending drive to the motoneurons $[33,35]$.

\section{Conclusions}

High-dose sodium bicarbonate intake $\left(0.4 \mathrm{~g} \cdot \mathrm{kg}^{-1}\right.$ body weight) improved high-intensity intermittent exercise performance in trained young men, with concomitant increased blood alkalosis. Sodium bicarbonate supplementation increased blood lactate levels at exhaustion and lowered rating of perceived exertion during intense intermittent exercise. The results indicate a link between improved fatigue resistance during high-intensity intermittent exercise and a sodium-bicarbonate-induced improved buffer capacity that may affect perceived exertion during intense intermittent exhaustive exercise.

\section{Competing interests}

The authors declare that they have no competing interests.

\section{Authors' contributions}

PK and MM developed the design of the study and carried out the data collection in cooperation with GE, who performed all blood analyses. PK, GE and MM performed the data treatment, including statistical analyses. PK and MM drafted the manuscript with the help of GE. All authors read and approved the manuscript.

\section{Acknowledgements}

We would like to thank the subjects for their participation and efforts, as well as Lee Wylie, Jamie R Blackwell, James Kelly, Sarah R. Jackman and Jonathan Ellis for their valuable technical assistance during the experiments. In addition, we would like to thank Dr Nikolai B. Nordsborg for his advice on the sodium bicarbonate intake protocol. 


\section{Author details}

${ }^{1}$ Department of Nutrition, Exercise and Sports, Section of Human Physiology, Copenhagen Centre for Team Sport and Health, University of Copenhagen, Copenhagen, Denmark. ${ }^{2}$ Sport and Health Sciences, College of Life and Environmental Sciences, St. Luke's Campus, University of Exeter, Exeter, UK. ${ }^{3}$ Democrite University of Thrace, Komotini 69100 , Greece. ${ }^{4}$ Faculty of Natural and Health Sciences, University of the Faroe Islands, Jónas Broncks gøta 25. 3rd floor, Tórshavn, Faroe Islands. ${ }^{5}$ Department of Food and Nutrition, and Sport Science, Center of Health and Human Performance, University of Gothenburg, Gothenburg, Sweden.

Received: 16 February 2015 Accepted: 22 May 2015

Published online: 04 June 2015

\section{References}

1. Fitts R. Cellular mechanism of muscle fatigue. Physiol Rev. 1994;74:49-94.

2. Keyser RE. Peripheral fatigue: high-energy phosphates and hydrogen ions. PM R. 2010;2:347-58

3. Nordsborg N, Mohr M, Pedersen LD, Nielsen JJ, Langberg H, Bangsbo J. Muscle interstitial potassium kinetics during intense exhaustive exercise: effect of previous arm exercise. Am J Physiol Regul Integr Comp Physiol. 2003;285:143-8.

4. Mohr M, Nordsborg N, Nielsen JJ, Pedersen LD, Fischer C, Krustrup P, et al. Potassium kinetics in human muscle interstitium during repeated intense exercise in relation to fatigue. Pflugers Arch. 2004;448:452-6.

5. Krustrup P, Mohr M, Steensberg A, Bencke J, Kjær M, Bangsbo J. Muscle and blood metabolites during a soccer game: implications for sprint performance. Med Sci Sport Exerc. 2006;38:1165-71.

6. Bendiksen M, Bischoff R, Randers MB, Mohr M, Rollo I, Suetta C, et al. The Copenhagen Soccer Test: Physiological Responses and Fatigue Development. Med Sci Sport Exerc. 2012;44:1595-603.

7. Krustrup P, Mohr M, Nybo L, Jensen JM, Nielsen JJ, Bangsbo J. The Yo-Yo IR2 test: physiological response, reliability, and application to elite soccer. Med Sci Sports Exerc. 2006;38:1666-73.

8. Bangsbo J, laia FM, Krustrup P. The Yo-Yo intermittent recovery test a useful tool for evaluation of physical performance in intermittent sports. Sports Med, 2008;38:37-51

9. Kilding AE, Overton C, Gleave J. Effects of caffeine, sodium bicarbonate, and their combined ingestion on high-intensity cycling performance. Int J Sport Nutr Exerc Metab. 2012;22:175-83.

10. Culbertson JY, Kreider RB, Greenwood M, Cooke M. Effects of beta-alanine on muscle carnosine and exercise performance: a review of the current literature. Nutr. 2010;2:75-98.

11. Bangsbo J, Madsen K, Kiens B, Richter EA. Effect of muscle acidity on muscle metabolism and fatigue during intense exercise in man. J Physiol. 1996:495:587-96.

12. Harris RC, Sale C. Beta-alanine supplementation in high-intensity exercise. Med Sport Sci. 2012;59:1-17.

13. Burke LM. Practical considerations for bicarbonate loading and sports performance. Nestle Nutr Inst Workshop Ser. 2013;75:15-26.

14. Peart DJ, Siegler JC, Vince RV. Practical recommendations for coaches and athletes: a meta-analysis of sodium bicarbonate use for athletic performance. J Strength Cond Res. 2012;26:1975-83.

15. Carr AJ, Slater GJ, Gore CJ, Dawson B, Burke LM. Effect of sodium bicarbonate on $\left[\mathrm{HCO}_{3}-\right], \mathrm{pH}$, and gastrointestinal symptoms. Int J Sport Nutr Exerc Metab. 2011;21:189-94.

16. Bishop D, Claudius B. Effects of induced metabolic alkalosis on prolonged intermittent-sprint performance. Med Sci Sport Exerc. 2005;37:759-67.

17. Siegler JC, Hirscher K. Sodium bicarbonate ingestion and boxing performance. J Strength Cond Res. 2010;24:103-8.

18. Mohr M, Nielsen JJ, Bangsbo J. Caffeine intake improves intense intermittent exercise performance and reduces muscle interstitial potassium accumulation. J Appl Physiol. 2011;111:1372-9.

19. Borg G. Borg's perceived exertion and pain scales. IL, USA: Champaign; 1998.

20. Mohr M, Krustrup P, Nielsen JJ, Nybo L, Rasmussen MK, Juel C, et al. Effect of two different intense training regimes on skeletal muscle ion transport systems and fatigue development. Am J Physiol Regul Interg Comp Physiol. 2007;292:R1594-602.

21. Bangsbo J, Mohr M. Fitness Testing in Football. Copenhagen, Denmark: Bangsbosport; 2012.
22. Juel C, Klarskov C, Nielsen JJ, Krustrup P, Mohr M, Bangsbo J. Effect of highintensity intermittent training on lactate and $\mathrm{H}+$ release from human skeletal muscle. Am J Physiol Endocrinol Metab. 2004;286:e245-51.

23. Saunders B, Sunderland C, Harris RC, Sale C. $\beta$-alanine supplementation improves YoYo intermittent recovery test performance. J Int Soc Sport Nutr. 2012;9:39.

24. laia FM, Thomassen M, Kolding H, Gunnarsson T, Wendell J, Rostgaard T, et al. Reduced volume but increased training intensity elevates muscle $\mathrm{Na}+-\mathrm{K}+$ pump alpha1-subunit and NHE1 expression as well as short-term work capacity in humans. Am J Physiol Regul Integr Comp Physiol. 2008:294:R966-74.

25. Bishop D, Edge J, Davis C, Goodman C. Induced metabolic alkalosis affects muscle metabolism and repeated-sprint ability. Med Sci Sports Exerc. 2004;36:807-13.

26. Pollo A, Carlino E, Benedetti F. Placebo mechanisms across different conditions: from clinical settings to physical performance. Phil Trans R Soc B. $2011 ; 366: 1790-8$.

27. Street D, Nielsen JJ, Bangsbo J, Juel C. Metabolic alkalosis reduces exerciseinduced acidosis and potassium accumulation in human skeletal muscle interstitium. J Physiol. 2005;566:481-9.

28. McKenna MJ, Bangsbo J, Renaud JM. Muscle K+, Nat, and Cl disturbances and $\mathrm{Na}+-\mathrm{K}+$ pump inactivation: implications for fatigue. J Appl Physiol. 1985;104:288-95.

29. Cairns SP, Lindinger MI. Do multiple ionic interactions contribute to skeletal muscle fatigue. J Physiol. 2008;586:4039-54.

30. Juel C, Pilegaard H, Nielsen JJ, Bangsbo J. Interstitial $\mathrm{K}(+)$ in human skeletal muscle during and after dynamic graded exercise determined by microdialysis. Am J Physiol Regul Integr Comp Physiol. 2000;278:R400-6.

31. Clausen $\mathrm{T} . \mathrm{Na}^{+}-\mathrm{K}^{+}$pump regulation and skeletal muscle contractility. Physiol Rev. 2003;83:1269-324.

32. Davis NW, Standen NB, Stanfield PR. ATP-dependent potassium channels of muscle cells: their properties, regulation, and possible functions. J Bioenerg Biomembr. 1991;23:509-35.

33. Gandevia SC. Spinal and supraspinal factors in human muscle fatigue. Physiol Rev. 2001;81:1725-89.

34. Amann M, Sidhu SK, Weavil JC, Mangum TS, Venturelli M. Autonomic responses to exercise: Group III/IV muscle afferents and fatigue. Auton Neurosci. 2014;188:19-23.

35. Nybo L, Secher NH. Cerebral perturbations provoked by prolonged exercise. Prog Neurobiol. 2004;72:223-61.

\section{Submit your next manuscript to BioMed Central and take full advantage of:}

- Convenient online submission

- Thorough peer review

- No space constraints or color figure charges

- Immediate publication on acceptance

- Inclusion in PubMed, CAS, Scopus and Google Scholar

- Research which is freely available for redistribution 